Aisyah Journal of Informatics and Electrical Engineering Universitas Aisyah Pringsewu

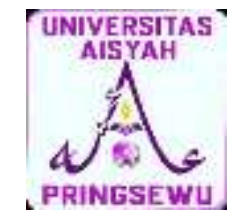

Journal Homepage

http://jti.aisyahuniversity.ac.id/index.php/AJIEE

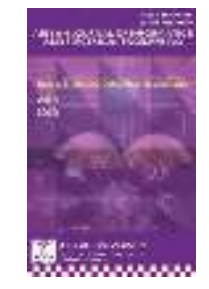

\title{
PERANCANGAN ARSITEKTUR JARINGAN LOCAL AREA NETWORK PADA SMP MUHAMMADIYAH O1 PRINGSEWU
}

\author{
Adi Prasetia Nanda ${ }^{1}$, Nur Aminudin ${ }^{2}$, Zulkifli ${ }^{3}$, M. Islamahdi ${ }^{4}$ \\ ${ }_{1,4}^{1,4}$ Prodi Sistem Informasi STMIK Pringsewu Lampung \\ ${ }^{2,3}$ Prodi Teknik Informatika Universitas Aisyah Pringsewu \\ e-mail : adiprasetiananda.artha@gmail.com ${ }^{l}$, nuraminudin.mti.ibi@gmail.com ${ }^{2}$, zulkiflist31@ gmail.com, \\ m.islamahdi@gmal.com ${ }^{3}$
}

\begin{abstract}
ABSTRAK
Jaringan komputer adalah jaringan telekomunikasi yang memungkinkan antar komputer untuk saling berkomunikasi dengan bertukar data. Pada SMP Muhammadiyah 01 Pringsewu sudah memanfaatkan kemajuan teknologi jaringan komputer, namun belum sepenuhnya terkoneksi dengan baik. Oleh karena itu dalam penelitian ini akan di bangun dan dikembangkan suatu arsitektur jaringan Lokal Area Network ( LAN ) yang terhubung dengan Internet Speedy. Perancangan arsitektur jaringan ini meliputi perancangan koneksi ke jaringan internet speedy, dan perancangan arsitektur lab komputer yang terhubung dengan jaringan di Sekolah Menengah Pertama Muhammadiyah 01 Pringsewu. Penelitian ini bertujuan untuk merancang teknologi yang ada beserta sistemnya, serta menambah teknologi dan system yang belum ada untuk dapat diintegrasikan ke dalam sebuah jaringan komputer yang terkoneksi dengan jaringan Internet Speedy. Diharapkan hasil penelitian ini akan membantu Guru dan Siswa SMP Muhammadiyah 01 Pringsewu dalam mencari dan mengembangkan informasi, sehingga dapat menunjang pembelajaran yang efektif dan efisien
\end{abstract}

\section{Keywords: Jaringan, LAN, Internet.}

\section{PENDAHULUAN}

\subsection{Latar Belakang Penelitian}

Pada jaringan komputer yang besar konfigurasi parameter TCP/IP pada masing-masing workstation akan sangat merepotkan dan membutuhkan waktu yang sangat lama, terutama ketika parameter TCP/IP seperti alamat IP dan subnetmask memerlukan perubahan. Jaringan LAN merupakan kepanjangan dari Local Area Network, yaitu jaringan komputer yang hanya mencakup wilayah kecil, seperti jaringan komputer warnet, gedung, kantor, rumah, sekolah atau yang lebih kecil.

Sekolah Menengah Pertama (SMP) Muhammadiyah 01 Pringsewu, merupakan salah satu sekolah di Kabupeten Pringsewu yang memiliki komputer yang belum mempunyai jaringan komputer, sehingga dalam mentransfer data di masing - masing komputer masih menggunakan perangkat keras semisal : flasdisk. Untuk mencetak data menggunakan printer hanya terbatas pada komputer tertentu yang memiliki printer. Untuk mendapatkan referensi yang aktual dengan media internet juga ditemukan kendala dikarenakan hanya komputer tertentu yang memiliki koneksi internet. Untuk itu penulis membuat rancangan arsitektur Jaringan Local Area Network (LAN) pada Sekolah Menengah Pertama (SMP) Muhammadiyah 01 Pringsewu.

\subsection{Rumusan Masalah}

Berdasarkan uraian latar belakang penelitian tersebut, maka dapat disimpulkan bahwa rumusan masalah dalam penelitian ini adalah "Bagaimana merancang arsitektur jaringan LAN pada Sekolah Menengah Pertama (SMP) Muhammadiyah 01 Pringsewu". 


\subsection{Batasan Masalah}

Dari uraian latar belakang dan rumusan masalah tersebut, maka pada penelitian ini peneliti hanya membahas tentang "rancangan arsitektur jaringan LAN".

\subsection{Tujuan Penelitian}

Pada penelitian ini bertujuan untuk membangun sebuah jaringan LAN pada Sekolah Menengah Pertama (SMP) Muhammadiyah 01 Pringsewu.

\subsection{Manfaat Penelitian}

Dengan adanya penelitian ini, Sekolah Menegah Pertama (SMP) Muhammadiyah 01 Pringsewu dapat mengimplementasikan jaringan LAN untuk lab agar seluruh distribusi file data dapat berjalan efektif dan efisien.

\section{TINJAUAN PUSTAKA}

\subsection{Jaringan Komputer}

Jaringan komputer pada hakekatnya adalah dua komputer atau lebih yang terhubung satu dengan yang lainnya. Perangkat yang dapat dihubungkan tidak terbatas pada komputer saja, melainkan termasuk printer dan perangkat-perangkat keras lainnya. Sebagai perhubung dapat digunakan kabel atau media lain yang tidak menggunakan kabel, misalnya gelombang radio, sinar inframerah dan Bluetooth.[1]

Jaringan komputer adalah sebuah sistem yang terdiri atas komputer-komputer yang didesain untuk dapat berbagi sumber daya (printer, CPU), berkomunikasi (surel, pesan instan), dan dapat mengakses informasi (peramban web). Tujuan dari jaringan komputer adalah agar dapat mencapai tujuannya, setiap bagian dari jaringan komputer dapat meminta dan memberikan layanan (service). Pihak yang meminta/menerima layanan disebut klien (client) dan yang memberikan/mengirim layanan disebut peladen (server). Desain ini disebut dengan sistem client-server, dan digunakan pada hampir seluruh aplikasi jaringan komputer.[2]

Jaringan Komputer adalah hubungan dua buah simpul (umumnya berupa komputer) atau lebih yang tujuan utamanya adalah untuk melakukan pertukaran data.[3]
Jaringan Komputer merupakan kumpulan dari perangkat keras dan lunak di dalam suatu sistem yang memiliki aturan tertentu untuk mengatur seluruh anggotanya dalam melakukan aktivitas komunikasi. Satu komputer yang terkoneksi ke jaringan menjadi satu node dari jaringan tersebut. Sedangkan host secara umum diartikan sebagai komputer yang terkoneksi ke jaringan yang dapat memberikan layanan jaringan (network service).[4]

Kristanto) menyebutkn bahwa Jaringan komputer merupakan sekelompok komputer otonom yang saling berhubungan satu sama lain, dengan menggunakan satu protocol kompunikasi sehingga selruh komputer yang saling terhubung tersebut dapat berbagi informasi, program, sumber daya dan juga dapat saling menggunakan perangkat keras lainnya secara bersamaan, seperti printer, harddisk dan lain sebagainya.

\subsection{LAN}

Local Area Network atau LAN, merupakan suatu Jenis Jaringan Komputer dengan mencakup wilayah lokal. Dengan menggunakan berbagai perangkat jaringan yang cukup sederhana dan populer, seperti menggunakan kabel UTP (Unshielded Twisted-Pair), Hub, Switch, Router, dan lain sebagainya.Contoh dari jaringan LAN seperti komputer-komputer yang saling terhubung di sekolah, di perusahaan, Warnet, maupun antar rumah tetangga yang masih mencakup wilayah LAN.[5]

Menurut Nasmul Irfan, ST dalam bukunya yang berjudul "Pengenalan dan Instalasi Jaringan" menjelaskan bahwa Jaringan Local Area Network (LAN) adalah jaringan yang dibatasi oleh area yang relative kecil, umumnya dibatasi oleh area lingkungan seperti sebuah perkantoran di sebuah gedung atau sebuah sekolah dan biasanya tidak jauh dari sekitar $1 \mathrm{~km}$ persegi..[6]

\section{METODE PENELITIAN \\ 3.1. METODE PENGUMPULAN DATA}

Metodologi yang penulis gunakan dalam penelitian jurnal ini adalah Analisis Deskriptif, yaitu metode penelitian dengan jenis Studi Kasus. Adapun teknik pengumpulan data yang digunakan antara lain :

a. Studi literatur, dilakukan dengan mencari pustaka yang menunjang penelitian yang akan dikerjakan. Pustaka tersebut dapat berupa buku, laporan jurnal, artikel, dsb.

b. Studi lapangan, studi ini dilakukan dengan melakukan observasi yaitu pengamatan dalam 
pengumpulan data yang dibutuhkan dengan catatan secara cermat dan sistematis.

c. Wawancara secara langsung kepada mayrakat yang berhubungan dengan masalah yang ada, dll. [7]

\section{PEMBAHASAN}

\subsection{Perancangan Arsitektur Jaringan LAN}

\section{Perancangan sistem jaringan.}

Pada proses perancangan arsitektur jaringan LAN tersebut diperlukan data-data untuk menentukan Jaringan yang dipergunakan. Diperoleh kerangka pemikiran sebagai berikut :

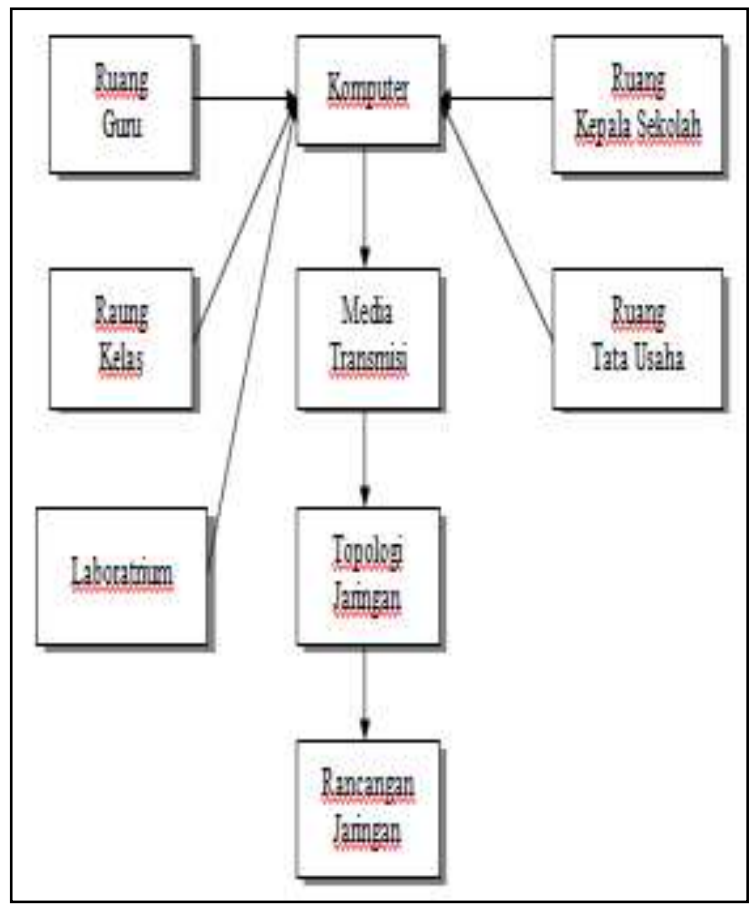

Gambar 1 Kerangka Pemikiran

\section{Topologi Jaringan}

Pada perancangan arsitektur Jaringan LAN diperlukan sebuah topologi, yaitu menggambarkan struktur dari suatu jaringan atau bagaimana sebuah jaringan yang dihubungkan. Dalam perancangan Jaringan di SMP N 1 Kerjo Karanganyar digunakan Topologi Star.

\section{Topologi}

Star merupakan bentuk topologi jaringan yang berupa konvergensi dari node tengah ke setiap node atau pengguna. Masing- masing workstation di hubungkan secara langsung ke Server atau Hub/Swich. Intinya topologi ini mengunakan Hub/Switch untuk menghubungkan dari komputer satu ke komputer yang lain.[8]

Kelebihan menggunakan topologi star antara lain :

1) Layout dan pemasangan kabel mudah.

2) Tidak akan mengganggu kinerja jaringan jika ada penambahan atau pengurangan terminal.

3) Mudah dalam pengolahan jaringan.

Kekurangan menggunakan topologi star, boros dalam penggunaan kabel.

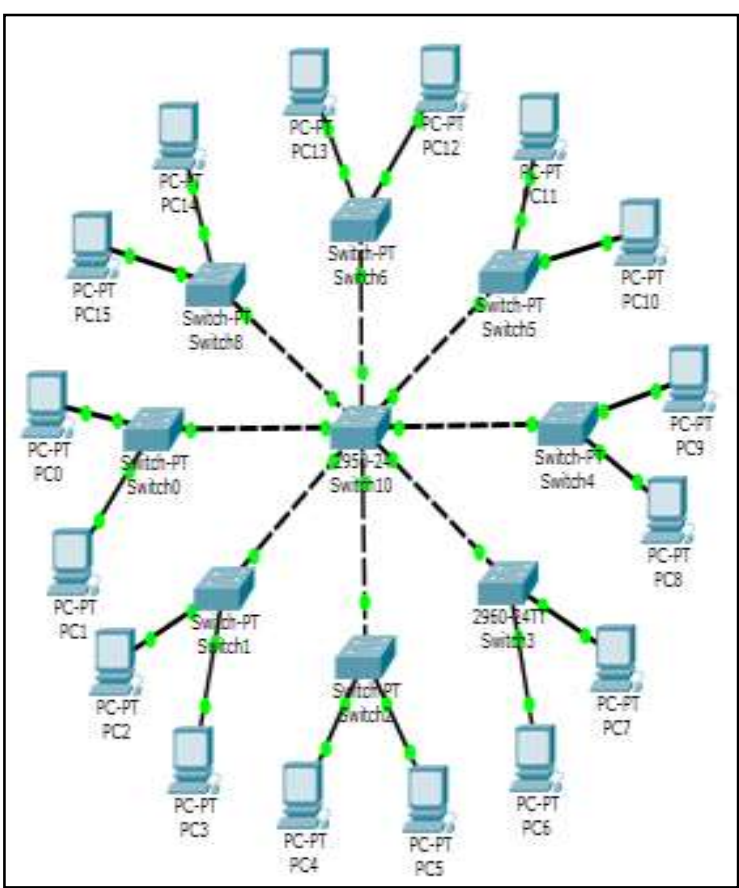

Gambar 2. Topologi star

\section{Jaringan Local Area Network (LAN)}

Local Area Network (LAN) adalah Suatu jaringan komputer yang menghubungkan komputer atau workstation yang satu dengan computer yang lain, misalnya dirumah atau diperkantoran. Jaraknya dibatasi sampai beberapa kilometer dan memiliki kecepatan koneksi antara 2 - 10 Mega Byte per sekon. [9]

Keuntungan menggunakan LAN adalah :

1. Akses data antar computer berlangsung cepat dan mudah

2. Dapat menghubungkan banyak komputer dapat terkoneksi ke internet

3. Back Up data berlangsung lebih cepat dan mudah

\section{Internet Protocol (IP) Address}

Modem ZTE $=$ 192.168.100.1

\begin{tabular}{|l|l|}
\hline Komputer & IP Address \\
\hline Komputer Server & 192.168 .30 .2 \\
\hline
\end{tabular}




\begin{tabular}{|l|l|}
\hline Komputer Kepala Sekolah & 192.168 .30 .3 \\
\hline Komputer Tata Usaha & $192.168 .30 .3 \mathrm{~s} / \mathrm{d}$ \\
& 192.168 .30 .5 \\
\hline Komputer Guru & $192.168 .30 .6 \mathrm{~s} / \mathrm{d}$ \\
& 192.168 .30 .21 \\
\hline Komputer Lab & $192.168 .30 .21 \mathrm{~s} / \mathrm{d}$ \\
& 192.168 .30 .41 \\
\hline
\end{tabular}

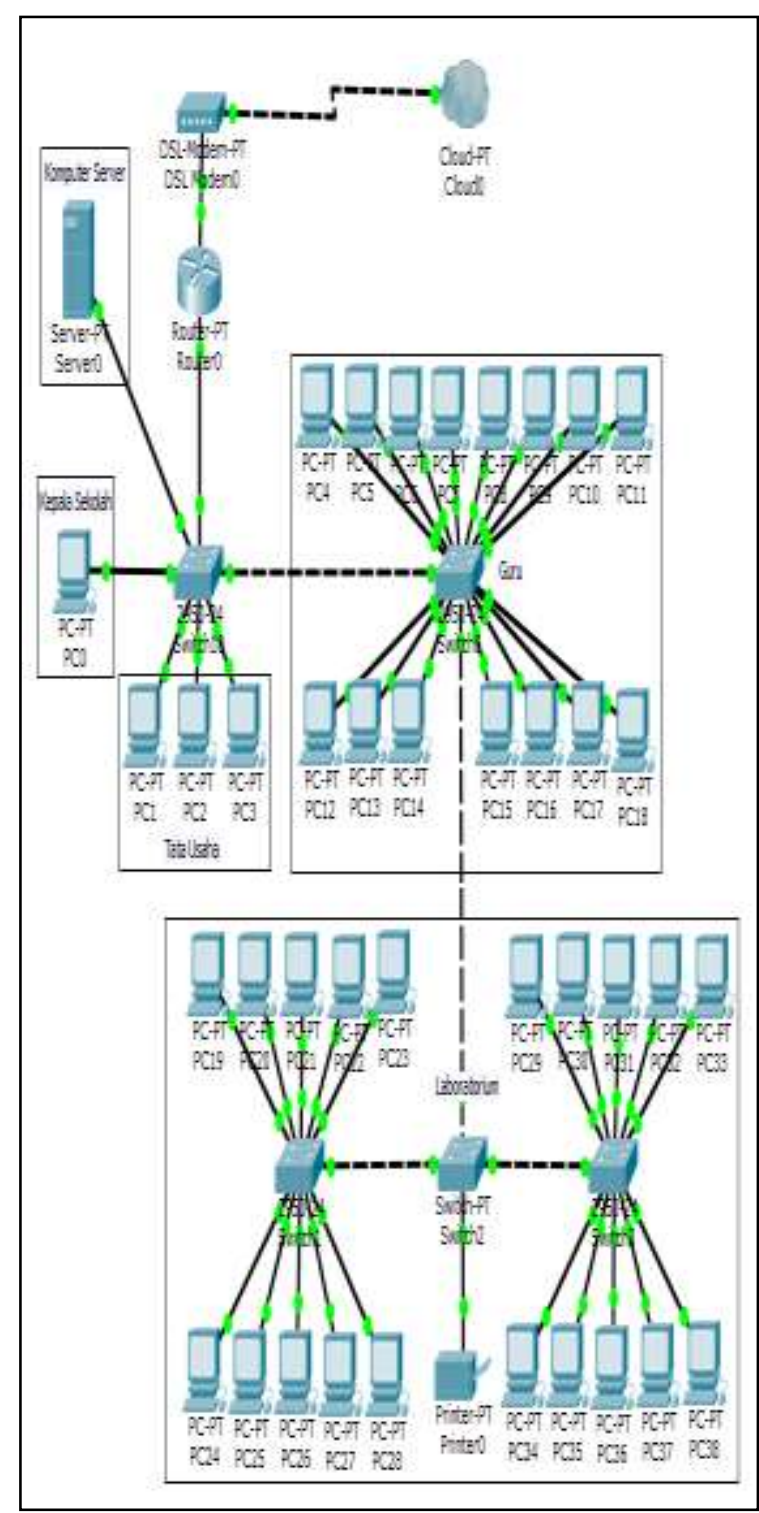

Gambar 3 Rancangan Local Area Network (LAN)

\section{Seting Jaringan}

\section{Seting IP pada Modem ZTE}

Dibuka web browser, lalu pada addres bar diketik : 192.168.1.1, dan lalu masukan User Name : admin dan Password : admin

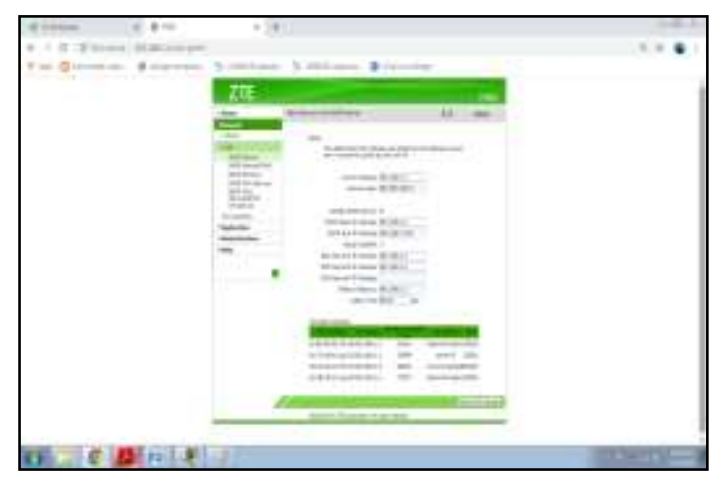

Gambar 4. Hasil Seting modem ZTE 


\section{Seting IP pada Komputer}

Konfigurasi TCP / IP pada Setian komputer

\begin{tabular}{|c|c|}
\hline \multicolumn{2}{|c|}{ Internet Protocol Version 4 (TCP/P U) Properties } \\
\hline \multicolumn{2}{|l|}{ General } \\
\hline \multicolumn{2}{|c|}{ 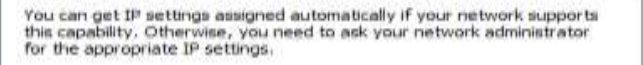 } \\
\hline \multicolumn{2}{|c|}{ Obtain an IP address automatically } \\
\hline \multicolumn{2}{|c|}{ a) Ume the following IP addrama: } \\
\hline IP addreus: & $192+160 \cdot 30+3$ \\
\hline Subnet maskt & $255,255,255,0$ \\
\hline Defoult gatewayi & $192,168,30,1$ \\
\hline \multicolumn{2}{|c|}{ Obtan Diss server address automatically } \\
\hline \multicolumn{2}{|c|}{ Use the following DNs server addresses! } \\
\hline Preferred DNS server: & $a, a, 8,8$ \\
\hline Alternate DNS merver: & $a \cdot a \cdot 4 \cdot 4$ \\
\hline \multirow[t]{2}{*}{$\square$ Validate settings upon exit } & Advanced... \\
\hline & OK Cancel \\
\hline
\end{tabular}

Gambar 5. Seting TCP/IP pada computer client

\section{Konfigurasi Sharing data}

Konfigurasi sharing data pada setiap komputer Client

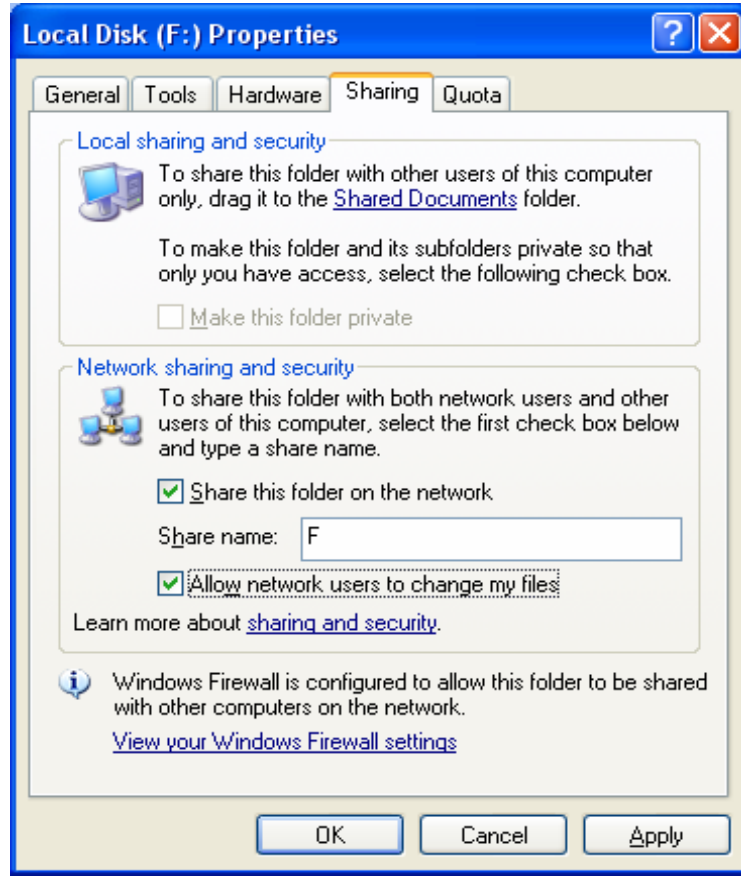

Gambar 6. Konfigurasi Sharing data pada komputer client

Konfigurasi Shareing printer

Konfigurasi sharing Printer

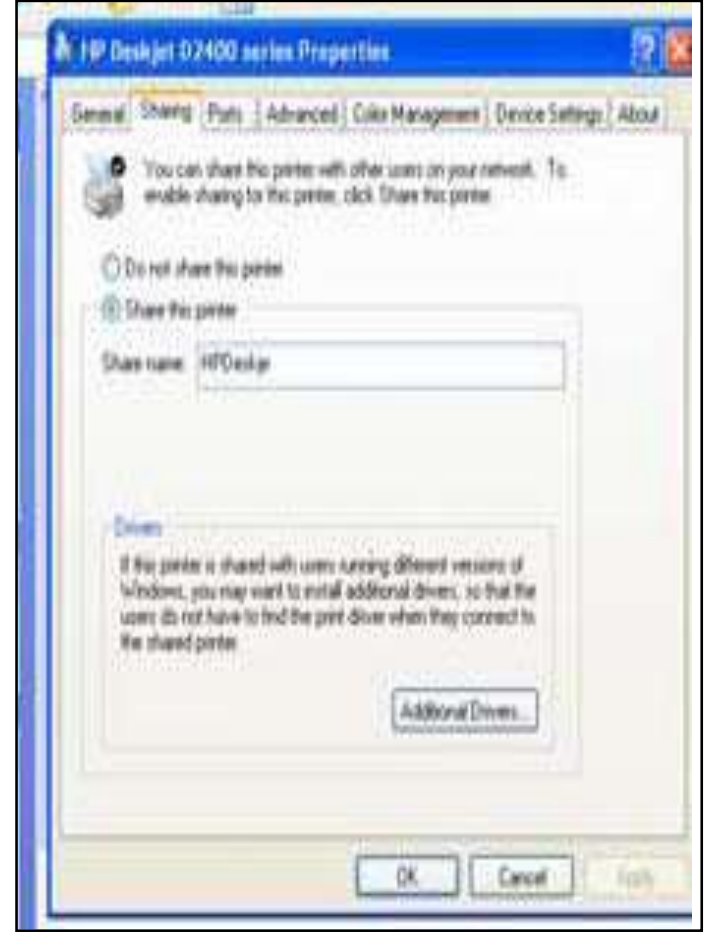

Gambar 7. Konfigurasi sharing printer

\section{Uji coba}

Uji coba reguest IP dari komputer client

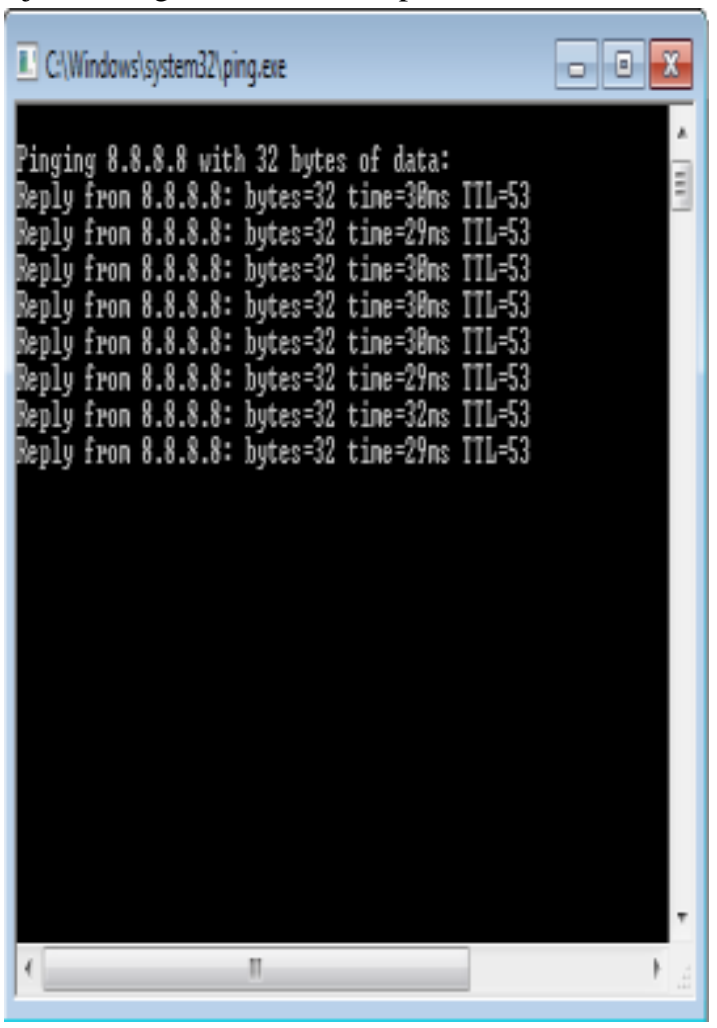

Gambar 8. Reques IP pada komputer client dari router gateway

Uji Coba test koneksi komputer client dengan router gateway 


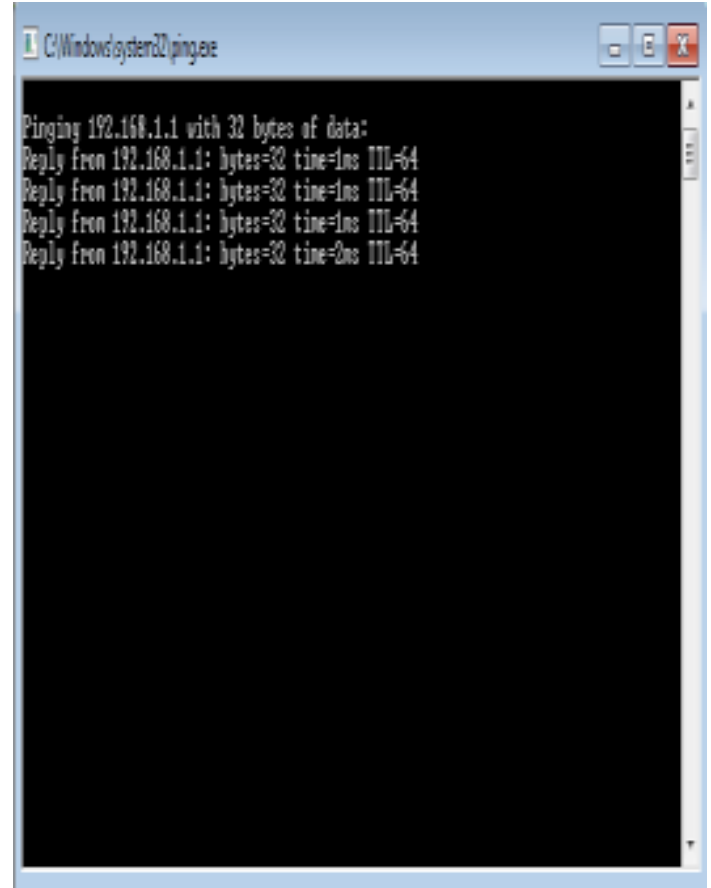

Gambar 9. Tes koneksi komputer client dengan router

Tes Koneksi

Tes koneksi internet komputer client

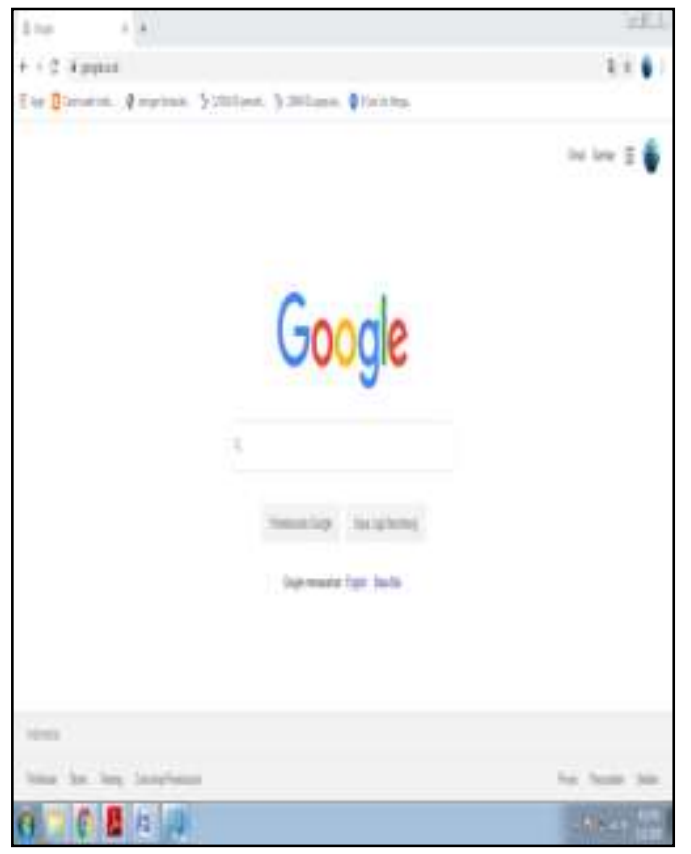

Gambar 10. Test koneksi komputer client dengan internet

\section{PENUTUP}

\subsection{Kesimpulan}

Hasil dari Perancangan arsitektur jaringan local area network (LAN) pada Smp Muhammadiyah 01 Pringsewu dapat memberikan gambaran rancangan sistem jaringan komputer yang dimasa yang akan datang dapat digunakan sebagai acuan untuk membangun suatu jaringan komputer yang baik serta efisien dan mudah untuk diterapkan.

\section{DAFTAR PUSTAKA}

[1] S. Susanto, "Perencanaan Local Area Network," J. Transform., vol. 6, no. 1, p. 10, 2008, doi: 10.26623/transformatika.v6i1.28.

[2] I. Journal, "Rancangan Jaringan Local Area Network Berbasis Windows Sekolah Menengah Pertama ( Smp ) Negeri 1 Kerjo," vol. 2, no. 3, pp. 19-22, 2013.

[3] P. Krisna, D. Cahya, W. A. Priyono, M. Sc, and G. Asmugi, "Perancangan Jaringan Local Area Network (LAN) untuk Layanan Video Conference dengan Standar WIFI 802.11G," Univ. Brawijaya, pp. 1-6, 2015.

[4] D. Alfurqon and S. Assegaff, "Analisis Dan Perancangan Jaringan Local Area Network Pada Laboratorium Smk Negeri 1 Kota Jambi," J. Manaj. Sist. Inf., vol. 3, no. 3, pp. 1149-1163, 2018.

[5] I. R. Rahadjeng and R. Puspitasari, "ANALISIS JARINGAN LOCAL AREA NETWORK (LAN) PADA PT. MUSTIKA RATU Tbk JAKARTA TIMUR," Prosisko, vol. 5, no. 1, pp. 53-60, 2018.

[6] A. Supriyanto, "Analisis Kelemahan Keamanan pada Jaringan Wireless," Anal. Keamanan Jar. Wirel., vol. XI, no. 1, pp. 3846, 2006.

[7] Susanto;Husaini, "Pengembangan Perancangan Jaringan Local Area Network (LAN) di RSIA Anugrah Medical Centre Metro," Mikrotik, vol. 7, no. 2, pp. 25-36, 2017.

[8] J. Arifin, "Perancangan Jaringan LAN dan WLAN Berbasis Mikrotik Pada Sekolah Menengah Kejuruan," J. Sisfokom (Sistem Inf. dan Komputer), vol. 2, no. 2, pp. 17-22, 2013, doi: 10.32736/sisfokom.v2i2.91.

[9] dan I. M. A. S. N.M.A.E.D. Wirastuti, I.G.A.K.D.D. Hartawan, "Perancangan Dan Instalasi Jaringan Komputer Local Area Network ( Lan ) Di Sekolah Dasar Negeri 2 Kintamani Bangli," vol. 15, no. September, pp. 37-42, 2016. 